\title{
REFORMA TRABALHISTA: ANÁLISE DA APLICAÇÃO NAS PRÁTICAS DE ADMISSÃO, FÉRIAS E RESCISÃO NAS INSTITUIÇÓES DE ENSINO SUPERIOR COMUNITÁRIAS DO RIO GRANDE DO SUL
}

\author{
Ana Cristine Heinen ${ }^{1}$ \\ Tiago Andregieski ${ }^{2}$ \\ Clari Schuh $^{3}$ \\ Marco Aurélio Batista de Sousa ${ }^{4}$
}

\begin{abstract}
Resumo: A pesquisa teve como objetivo analisar a aplicação das alterações da reforma trabalhista nas práticas de admissão, férias e rescisão nas Instituiçôes de Ensino Superior Comunitárias do Rio Grande do Sul. Para tanto, utilizou-se da pesquisa descritiva e da abordagem qualitativa, sendo os dados coletados por questionário direcionados aos responsáveis pela gestão de pessoas nestas instituiçôes. Os resultados apontam que na prática de admissão, as instituiçôes não estão se utilizando dos contratos de trabalho intermitente e do teletrabalho, diferentemente da terceirização da atividade fim que é utilizada. Na prática de férias, as Instituiçôes estão se utilizado do fracionamento de férias e nas rescisōes está sendo considerado as particularidades de cada caso.
\end{abstract}

Palavras-chave: Reforma trabalhista. Prática trabalhista. IES comunitárias.

1 Mestra em Ciências Contábeis pela Universidade do Vale do Rio dos Sinos (UNISINOS). Professora da Universidade de Santa Cruz do Sul.

2 Bacharel em Ciências Contábeis pela Universidade de Santa Cruz do Sul.

3 Doutora em Contabilidade pela Universidade do Vale do Rio dos Sinos (UNISINOS). Professora da Universidade de Santa Cruz do Sul.

4 Doutor em Engenharia e Gestão do Conhecimento pela Universidade Federal de Santa Catarina (UFSC). Professor da Universidade Federal de Mato Grosso do Sul, Campus de Três Lagoas. 


\title{
LABOR REFORM: ANALISYS OF THE PRACTICES OF ADMISSION, VACATIONS AND TERMINATIONS AT COMMUNITY HIGHER EDUCATIONS INSTITUTIONS IN RIO GRANDE DO SUL
}

\begin{abstract}
The research goal was to analyze the application of changes in labor reform in the practices of admission, vacations and termination at Community Higher Education Institutions in Rio Grande do Sul. For that, it was used descriptive research and a qualitative approach, with data collected through a questionnaire directed to those responsible for managing people in these institutions. The results show that in the practice of admission, the institutions are not using intermittent work contracts and telework, unlike the outsourcing of the core activity that is used. As to the vacation practices, the Institutions are using the fractioning of vacations and as to the terminations the particularities of each case are being considered.
\end{abstract}

Keywords: Labor Reform, Labor Practices, community IES.

\section{INTRODUÇÃO}

A Consolidação das Leis do Trabalho (CLT), de 1943, mesmo com mudanças ao longo de sua existência, não atende mais às necessidades das novas formas de trabalho. Nesse sentido, a modernização trabalhista, além de privilegiar o diálogo entre empregador e empregado e buscar a sustentabilidade das empresas introduziu novas formas de regulamentação de trabalho, como o teletrabalho e o intermitente (CARVALHO; CARVALHO NETO; GIRÃO 2017).

A reforma trabalhista era necessária, não somente para atualizar a legislação, mas também para possibilitar novas contrataçóes e criar mais possibilidades de trabalho para as pessoas. $\mathrm{O}$ Estado busca alternativas para se posicionar perante as relaçôes entre trabalhadores e empregadores, optando por uma filosofia mais liberal e menos intervencionista (CARVALHO; CARVALHO NETO; GIRÃO 2017).

Certo que, haverá discussões acerca da nova Lei, mudanças acontecerão para adequar às necessidades da sociedade no sentido de aperfeiçoar as relações entre empregador e empregado. Carvalho, Carvalho Neto e Girão (2017) concluem que é preciso entender que a modernização nas relaçóes de trabalho não deve servir nem para proteger demais o trabalhador e nem para tirar seus direitos, mas para adaptação ao real mercado de trabalho.

Diante deste contexto surge o seguinte questionamento: como está a aplicação das regras trabalhistas nas práticas de admissão, férias e rescisão, frente às mudanças da reforma trabalhista nas Instituiçóes de Ensino Superior integrantes do Consórcio das Universidades Comunitárias Gaúchas (COMUNG)?

Além desta introdução, este artigo está estruturado em mais quatro seçôes. $\mathrm{Na}$ segunda seção é apresentado o referencial teórico, que trata da reforma trabalhista. $\mathrm{Na}$ terceira seção consta o desenvolvimento metodológico da pesquisa. 
Os resultados são apresentados na seção quatro. Por último, a seção cinco apresenta as consideraçóes finais.

\section{REFORMA TRABALHISTA}

A Lei no $13.467 / 2017$ buscou simplificar a legislação, reduzir a burocracia, ajustar a Lei às novas formas de trabalhar, reduzir a informalidade, diminuir o número de conflitos e obter segurança jurídica (BRASIL, 2017; ROCHA, 2017).

Ao todo, a reforma trabalhista trouxe 106 mudanças para a CLT, sendo 54 artigos alterados; 43 novos artigos e 9 artigos revogados. Estas mudanças procuram valorizar o diálogo entre trabalhadores e empresas e reduzir burocracias. Como principais avanços, pode-se citar as novas formas de trabalho como o contrato de trabalho intermitente; o teletrabalho; a flexibilização do trabalho em tempo parcial; a possibilidade de fracionamento do gozo de férias e novos procedimentos para a rescisão do contrato (CASSAR, 2017).

\subsection{PRÁTICA DE ADMISSÁO ANTES DA REFORMA}

A admissão é quando o empregador registra o funcionário, momento em que ele passa a ter vínculo empregatício com a empregadora. Nesse ato deve-se apresentar ao empregador as regras da empresa; as cláusulas do contrato de trabalho e as normas das Convençóes ou Acordos Coletivos de Trabalho além das regulamentaçóes relativas à Segurança e Medicina do Trabalho, e quando a instituição possuir, o regulamento interno da instituição (HEINEN, 2017).

Todos os empregados regidos pela CLT, são submetidos a procedimentos aplicáveis para fins de admissão devendo entregar os documentos pessoais para registro de empregado; atestado de saúde ocupacional; cadastro de pessoa física; carteira de identidade; carteira de trabalho e previdência social; uma foto $3 \times 4$; título de eleitor; certificado de reservista para homens; carteira nacional de habilitaçáo; comprovante de residência; comprovante de escolaridade; e-mail e telefone. Para fins de recebimento de salário família se for o caso certidáo de nascimento de filhos menor de 14 anos; carteira de vacinaçáo de filhos menor de 7 anos; comprovante de matricula e frequência escolar de filhos maiores de 7 anos (OLIVEIRA, 2017).

Por exigência legal, estes documentados são necessários para atender o que determina o a CLT, e, segundo Oliveira (2006, p. 25), "a empresa regida pela CLT, ao admitir um empregado, deverá registrá-lo no livro, na ficha ou no sistema eletrônico". Após o registro do funcionário, o empregador deve elaborar os documentos e concluir a admissão com a coleta da assinatura nos seguintes documentos: ficha de registro de empregados; contrato de trabalho; ficha de salário família; outros documentos de acordo com as regras da empresa (CASSAR, 2017). 


\subsection{PRÁTICA DE ADMISSÁO APÓS A REFORMA TRABALHISTA}

A partir da reforma, foi incluído o contrato individual para a prestação de trabalho intermitente, onde a prestação de serviços é com subordinação, não é contínua, ocorrendo com alternância de períodos de prestação de serviços e inatividade, determinados em horas, dias ou meses, independentemente do tipo de atividade do empregado e do empregador, com exceção dos aeronautas, que possuem legislação própria (REIS, 2016).

Tanto para o empregador quanto para o empregado, há flexibilidade nas condiçóes de trabalho, tendo em vista que com a alternância nos períodos de prestação de serviço e inatividade, este empregado poderá trabalhar para mais empregadores, estando garantido o pagamento de férias após 12 meses de trabalho, décimo terceiro salário proporcional e todos os adicionais legais previstos (REIS, 2016).

Ademais, dentre as alteraçóes da reforma trabalhista, destaca-se também o contrato de teletrabalho, definido como a prestação de serviços fora das instalaçôes da empresa, utilizando-se de tecnologias da informação e comunicação. As condiçóes para alteraçáo de trabalho presencial para teletrabalho devem ser de acordo entre empregador e empregado, com prazo mínimo de 15 dias. Além disso, o contrato de trabalho deverá dispor sobre a aquisição e manutenção de equipamentos e infraestrutura necessária, não integrando estes para fins de remuneração do empregado. O contrato de teletrabalho deverá ser avaliado de acordo com a necessidade de cada empresa, considerando especificamente a atividade da empresa e o serviço que o empregado irá prestar (CASSAR, 2017).

Neste contexto, cita-se também a terceirização, que é a transferência de serviços feita pela contratante para empresa intermediária para a execução de qualquer atividade, inclusive sua atividade principal, mediante contrato de prestaçáo de serviços, a Lei ${ }^{\circ} 13.467$ de 2017, impôs limites em alguns termos como não poder figurar como contratada pessoa jurídica em que sócios ou titulares tenham sido empregados ou trabalhadores sem vínculo empregatício da contratante nos últimos 18 meses e, o empregado que for demitido não poderá ser funcionário na empresa prestadora de serviços, antes do decurso do prazo de 18 meses a contar da sua demissão (BRASIL, 2017)

Após apresentação das práticas de admissão antes e após a reforma trabalhista, será abordado a seguir a prática de férias.

\subsection{PRÁTICA DE FÉRIAS}

As férias são o período de descanso que o empregado tem direito após cada período de um ano de trabalho, período este chamado de aquisitivo. Garantidas pela CLT entende-se que as férias são um direito essencial ao empregado, para fins de garantir sua segurança e saúde no trabalho (BRASIL, 1988).

Passado o período aquisitivo, há o período concessivo, onde o empregado tem o prazo de um ano para usufruir 30 dias de férias. Caso não sejam concedidas as 
férias no prazo legal, estas deverão ser pagas em dobro pelo empregador. O período de gozo das férias é definido pelo empregador, independentemente da concordância do empregado. Para a concessão do período de gozo das férias, deve o empregador observar 30 dias corridos, quando não houver faltado ao serviço mais de 5 vezes; 24 dias corridos, quando não houver tido de 6 a 14 faltas; 18 dias corridos, quando não houver tido de 15 a 23 faltas; 12 dias corridos, quando houver tido de 24 a 32 faltas, não sendo permitido ao empregador descontar deste período as faltas que ele teve no serviço (BRASIL, 1943; 1998).

Para o empregado que trabalhar em regime parcial, as regras foram alteradas, após a reforma trabalhista. Para o gozo das férias, pode o empregado usufruir os dias normais de férias, ou seja, 30 dias, tendo também, por sua opção, a possibilidade de converter 10 dias em abono pecuniário. Caso o empregado opte pelo abono pecuniário, este deve ser solicitado ao empregador até 15 dias antes do término do período aquisitivo (BRASIL, 1943).

Em relação ao tratamento tributário do abono pecuniário, não há incidência de INSS, IR e FGTS. Por fim, o pagamento das férias se dará até 2 dias antes do início das férias (BRASIL, 2009).

\subsection{PRÁTICA DE FÉRIAS APÓS A REFORMA TRABALHISTA}

Antes da reforma trabalhista, a concessão das férias pelo empregador deveria ser em um só período, nos 12 meses subsequentes à data de aquisição do direito a férias. Havia previsão de que somente em casos excepcionais poderiam ser concedidas férias em 2 períodos, sendo que um deles não poderia ser inferior a 10 dias corridos e, aos menores de 18 anos e aos maiores de 50 anos, as férias deveriam ser concedidas de uma só vez. A reforma trabalhista altera a legislação na prática de férias, nos seguintes termos apresentados no Quadro 1.

Quadro 1 - Alteração da prática de férias

\begin{tabular}{|c|c|}
\hline Texto anterior & Reforma trabalhista \\
\hline Art. 134 (...): & Art. 134 (...): \\
\hline $\begin{array}{l}\$ 1 \text { 10 Somente em casos excepcionais serão as } \\
\text { férias concedidas em } 2 \text { (dois) períodos, um dos } \\
\text { quais náo poderá ser inferior a } 10 \text { (dez) dias } \\
\text { corridos. }\end{array}$ & $\begin{array}{l}\$ \mathbf{1 0}^{\mathbf{0}} \text { Desde que haja concordância do } \\
\text { empregado, as férias poderão ser usufruídas } \\
\text { em até três períodos, sendo que um deles não } \\
\text { poderá ser inferior a quatorze dias corridos e os } \\
\text { demais náo poderáo ser inferiores a cinco dias } \\
\text { corridos, cada um. }\end{array}$ \\
\hline \multirow{2}{*}{$\begin{array}{l}\text { \$ 20 Aos menores de } 18 \text { (dezoito) anos e aos } \\
\text { maiores de } 50 \text { (cinquenta) anos de idade, as } \\
\text { férias serão sempre concedidas de uma só vez. }\end{array}$} & $\$ \mathfrak{\$ 2}$ (Revogado) \\
\hline & $\begin{array}{l}\$ 3^{\circ} \text { É vedado o início das férias no período } \\
\text { de dois dias que antecede feriado ou dia de } \\
\text { descanso semanal remunerado. }\end{array}$ \\
\hline
\end{tabular}

Fonte: Brasil (2017). 
Em relação às alteraçôes na prática de férias, o empregador tem liberdade para organizar os períodos de descanso dos seus funcionários, podendo fazê-las de forma que não ocorra impactos na sua atividade.

\subsection{PRÁTICA DE RESCISÃO}

A rescisão do contrato de trabalho aponta o fim do vínculo empregatício, o momento em que são cessadas as obrigaçôes definidas no contrato de trabalho. As formas de rescindir um contrato de trabalho, mais praticadas são a rescisão sem justa causa, por pedido do empregado e por término de contrato de experiência (OLIVEIRA, 2006).

\section{a) Rescisáo sem justa causa}

A rescisão sem justa causa acontece por iniciativa do empregador. Ocorre nos casos em que há contratos com prazo indeterminado e antecipaçôes de término de contrato. Quando o desligamento é sem justa causa, o empregado possui direito ao aviso prévio, podendo ser trabalhado ou indenizado (BRASIL, 2003).

$\mathrm{O}$ aviso prévio trabalhado dado pelo empregador ao empregado será de 30 dias e pago na forma de salário e demais remuneraçóes adicionais. Deve-se reduzir a jornada do empregado em 2 horas diárias ou 7 dias corridos, sem prejuízo da remuneração. Caso o empregado consiga outro emprego antes do término do aviso prévio, fica dispensado seu cumprimento, sendo que neste caso o recebimento será proporcional aos dias trabalhados (BRASIL, 2003).

Quando o aviso prévio for indenizatório, o funcionário receberá o pagamento em forma de pecúnia, inclusive contando este período como tempo de serviço. Quando a rescisão se dá por iniciativa da empresa, além do aviso prévio, são direitos do empregado: saldo de salário e adicionais; $13^{\circ}$ salário; férias vencidas e proporcionais mais um terço. Além das verbas rescisórias informadas, o empregador ainda terá que efetuar o pagamento da multa rescisória de $50 \%$ sobre o valor base para fins rescisórios atualizado do FGTS (BRASIL, 2003).

\section{b) Rescisáo por pedido do empregado}

Ocorre quando a iniciativa de rescindir o contrato de trabalho é do empregado. $\mathrm{O}$ trabalhador deverá comunicar o empregador através do aviso prévio com antecedência de 30 dias, sob pena de o empregador descontar o salário correspondente a este período. Na rescisão por iniciativa do empregado, são direitos em verbas trabalhistas: saldo de salário e adicionais; $13^{\circ}$ salário; férias vencidas e proporcionais mais um terço. Para está modalidade de rescisão, não há multa sobre o FGTS e o saldo depositado na sua conta vinculada ficará retido (BRASIL, 1943). 


\section{c) Rescisáo por término do contrato de experiência}

Tendo em vista este momento de adaptaçáo, no caso de uma das partes desejar rescindir o contrato de trabalho, terá que ser na data determinada em contrato.

Caso o empregador decida romper o contrato de trabalho antes do dia determinado, deverá indenizá-lo com a remuneração da metade dos dias que faltam para o término do contrato. Caso contrário, sendo o término de contrato antecipado por parte do empregado, o empregador deve descontar a título indenizatório, o valor equivalente à metade dos dias que restam para findar o contrato de trabalho (BRASIL, 1943).

Nos casos de rescisão por término de contrato de trabalho na data determinada, as verbas rescisórias a que o trabalhador terá direito são: saldo de salário e adicionais; $13^{\circ}$ salário; férias proporcionais mais um terço. Para está modalidade de rescisão, não há multa sobre o FGTS, porém o trabalhador tem o direito ao FGTS sobre os valores pagos na rescisao, que será depositado em conta vinculada.

\subsection{PRÁTICA DE RESCISÁO APÓS A REFORMA TRABALHISTA}

Com a reforma trabalhista, muitas atividades da prática de rescisão não sofreram alteraçóes, porém requer atenção em casos específicos, como a extinção do ato de homologação sindical, o prazo unificado para pagamento das verbas rescisórias e o novo modelo de rescisáo por acordo (OLIVEIRA, 2006).

A homologação de rescisão, prevista na CLT, estabelecia que o recibo de quitação de rescisão do contrato de trabalho de empregado com mais de um ano de serviço somente teria validade quando realizado com assistência do sindicato da categoria ou perante autoridade do Ministério do Trabalho, foi revogada pela reforma trabalhista, conforme evidencia o Quadro 2.

Quadro 2 - Alteração da homologação sindical

\begin{tabular}{|c|c|}
\hline Texto anterior & Reforma trabalhista \\
\hline $\begin{array}{l}\text { Art. 477. É assegurado a todo empregado, não } \\
\text { existindo prazo estipulado para a terminaçáo } \\
\text { do respectivo contrato, e quando não haja } \\
\text { ele dado motivo para cessação das relaçóes de } \\
\text { trabalho, o direito de haver do empregador uma } \\
\text { indenização, paga na base da maior remuneraçáo } \\
\text { que tenha percebido na mesma empresa. }\end{array}$ & $\begin{array}{l}\text { Art. 477. Na extinção do contrato de trabalho, } \\
\text { o empregador deverá proceder à anotaçáo na } \\
\text { Carteira de Trabalho e Previdência Social, } \\
\text { comunicar a dispensa aos órgáos competentes e } \\
\text { realizar o pagamento das verbas rescisórias no } \\
\text { prazo e na forma estabelecidas neste artigo. }\end{array}$ \\
\hline $\begin{array}{l}\text { \$10 O pedido de demissão ou recibo de quitação } \\
\text { de rescisão, do contrato de trabalho, firmado } \\
\text { por empregado com mais de } 1 \text { ano de serviço, } \\
\text { só será válido quando feito com a assistência do } \\
\text { respectivo Sindicato ou perante a autoridade do } \\
\text { Ministério do Trabalho e Previdência Social. }\end{array}$ & $\$ 1^{\circ}$ (Revogado) \\
\hline
\end{tabular}

Fonte: Brasil (2017). 
A partir da vigência da reforma trabalhista, empregado e empregador estarão desobrigados da homologação junto ao sindicato, podendo formalizar o desligamento na própria empresa.

Outra mudança foi o prazo de pagamento das verbas rescisórias, tornandose mais clara a legislação quanto ao prazo para o pagamento das verbas rescisórias, unificando-se para qualquer modalidade de rescisão o prazo de dez dias.

Além das modificações quanto à homologação sindical e alteração no prazo para pagamento das verbas rescisórias, a reforma trabalhista possibilitou a rescisão do contrato por acordo. Neste tipo de rescisão, as verbas trabalhistas devidas serão a metade do aviso prévio, se indenizado, a metade da indenizaçáo sobre o saldo do FGTS e as demais verbas rescisórias na integralidade. Nesta modalidade o empregado poderá levantar $80 \%$ do valor dos depósitos do FGTS e não terá direito ao recebimento do seguro-desemprego (BRASIL, 1990).

\section{METODOLOGIA}

Esta pesquisa é classificada como descritiva, por descrever os fatos e os fenômenos pertinentes à esta realidade (MATIAS-PEREIRA, 2012).

Para tanto, inicialmente foi realizado uma entrevista semiestruturada com o responsável do setor de Recursos Humanos (RH) da Universidade de Santa Cruz do Sul (UNISC) com o propósito de entender as rotinas pertinentes da aplicação nas práticas de admissão, férias e rescisão. Após, elaborou-se um questionário com questôes predominantemente fechadas, o qual foi validado pelo responsável do RH da Unisc, e encaminhado por e-mail aos responsáveis pelo setor de $\mathrm{RH}$ das demais Instituiçôes (14) que compóem o Consórcio das Universidades Comunitárias Gaúchas (COMUNG).

Vale ressaltar que a escolha pela entrevista realizada com o responsável do RH da UNISC ocorreu em função da acessibilidade dos pesquisadores a este funcionário, o que não foi possível com os representantes das demais instituiçóes, por motivos de tempo e localização geográfica, tornando-se pertinente o envio de questionários para os e-mails destas pessoas.

Assim, das 15 IES, além da IES que validou o questionário, outras 6 retornaram o questionário via e-mail, totalizando 7 respostas, ou seja, 46,67\% das Instituiçóes de Ensino Superior do Comung são a amostra desta pesquisa.

Após o recebimento destes dados e informaçóes eles foram agrupados e analisados por meio da abordagem qualitativa destacando as características destas Instituiçôes e a realidade das práticas por elas adotadas quando admissão, férias e rescisão de funcionários (GERHARDT; SILVEIRA, 2009).

\section{ANÁLISE DOS DADOS E RESULTADOS}

Em 1993, um grupo de Instituiçôes do Rio Grande do Sul firmaram um Protocolo de Ação Conjunta, constituindo o Consórcio das Universidades 
Comunitárias Gaúchas, o Comung Constituído oficialmente em 1996, representou a materializaçáo de uma série de conquistas, tais como: programas e experiências compartilhadas; avaliação institucional; intercâmbios de professores e de alunos; qualificação e treinamento de funcionários e professores e fóruns de tecnologia da informação; integração entre diversos segmentos, como assessorias jurídicas, recursos humanos, assessorias de comunicação e bibliotecas (COMUNG, 2018).

As Instituições que formam o Consórcio são: Universidade Feevale; Pontifícia Universidade Católica do Rio Grande do Sul; Universidade Católica de Pelotas; Universidade de Caxias do Sul; Universidade de Cruz Alta; Universidade Regional do Noroeste do Estado do Rio Grande do Sul; Universidade de Santa Cruz do Sul; Universidade do Vale do Rio dos Sinos; Universidade do Vale do Taquari; Universidade de Passo Fundo; Universidade da Região da Campanha; Universidade Regional Integrada do Alto Uruguai e das Missóes; Centro Universitário Franciscano; Centro Universitário Metodista e Centro Universitário La Salle (COMUNG, 2018).

\subsection{REFORMA TRABALHISTA}

Dentre as IES respondentes à pesquisa, 50\% delas mencionaram estar aplicando aos poucos as alteraçóes trazidas pela reforma trabalhista enquanto as demais estão aplicando-as integralmente. Dentre as que mencionaram aplicar algumas cláusulas cita-se a Universidade de Santa Cruz do Sul que destaca que algumas das alterações não têm sido aplicadas devido a estratégias de gestáo e cumprimento de cláusulas de convenção coletiva, como por exemplo, horas initinere e prazo para pagamento de rescisóes que foi mantida a regra anterior.

\subsubsection{Aplicação da reforma trabalhista na prática de admissáo}

$\mathrm{Na}$ prática de admissão, as Instituiçôes mencionaram que apesar da flexibilidade para contratação de pessoas, não estão se utilizando do contrato de trabalho intermitente, tendo em vista que, suas atividades são regulares e em período integral, não passando por períodos de inatividade onde se aplica esta condição.

Da mesma forma, a contrataçáo pelo regime do teletrabalho de acordo com a IES náo se torna viável, visto que suas atividades presencial. No caso da prestaçáo de serviços através da terceirização, na UNISC aplica-se esta prática, principalmente quando da contratação de professores para ministrar aulas em seus cursos de pósgraduação mais especificamente à especialização, o que é comum também para $25 \%$ das IES amostra do estudo.

\subsubsection{Aplicação da reforma trabalhista na prática de férias}

O retorno de uma das IES, amostra da pesquisa, aponta que a flexibilizaçáo na prática de férias está sendo muito utilizada, pois o fato de poder usufruir do período de férias em até três períodos permite que a instituição consiga organizar a sua estrutura para náo acarretar em acúmulo de atividades e para o funcionário 
tornando-se assim benéfico, pois gozará de períodos de férias em momentos distintos durante o ano, como também acontece na grande maioria das outras IES.

\subsubsection{Aplicação da reforma trabalhista na prática de rescisáo}

Diante da modalidade de rescisão por acordo, 50\% das Instituições mencionaram que estão utilizando-se desta modalidade. Tendo em vista o número de colaboradores na instituição e que a liberação deste modelo de rescisão poderia causar um excesso de pedidos de acordo por parte dos funcionários, a UNISC estabeleceu que esta modalidade de rescisão por acordo seria utilizado em caso de redução de quadro. Portanto, caso algum funcionário de algum setor em que a instituição tenha como estratégia a redução de quadro, esta rescisão poderá ser nos moldes da rescisão por acordo, visto que atenderá ambas as partes.

Dentre as Instituiçóes de ensino que responderam à pesquisa, 67\% declararam ter critérios para realização da rescisão por acordo, porém não os informaram. $\mathrm{Na}$ sequência, as demais Instituiçóes, realizam a rescisão por acordo em casos específicos de redução de quadro.

\subsection{MUDANÇAS ORGANIZACIONAIS PARA APLICAÇÃO DA REFORMA TRABALHISTA}

A UNISC iniciou a análise para aplicação das alterações da reforma trabalhista, elencando as principais modificações que poderiam ser benéficas à instituição e após, todos estes temas foram verificados pelo setor jurídico. A instituição primeiramente recorreu a cursos e treinamentos para aprimorar o conhecimento sobre o tema, na sequência estabeleceu parcerias e troca de informaçóes com outras IES e também necessitou realizar ajustes no seu sistema de tecnologia da informação para atender as novas demandas.

As medidas necessárias para viabilizar a aplicação das alterações da reforma trabalhista nas práticas de admissão, férias e rescisão conforme mostra o Gráfico 1 foram: 
Gráfico 1 - Medidas para aplicação da reforma trabalhista

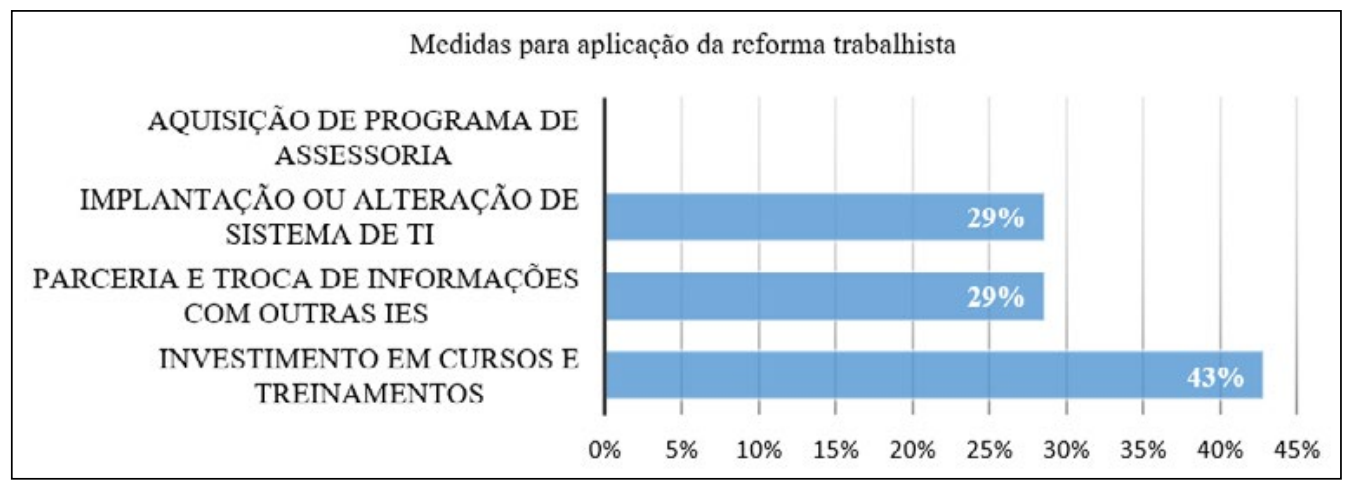

Fonte: Elaborado pelos autores

Assim, 43\% das Instituiçóes respondentes apontaram o investimento em cursos e treinamentos, pois além de se tratar de um tema novo para o setor de recursos humanos, há a necessidade de conhecer os impactos que a mesma proporcionaria. $\mathrm{Na}$ sequência, 29\% delas buscaram parcerias e troca de informaçóes com as demais IES do Comung, bem como necessitou de implantação ou alteração de sistema de Tecnologia da Informação e Comunicação para adequação das alteraçóes.

\section{CONSIDERAÇÓESS FINAIS}

A pesquisa teve por objetivo analisar a aplicação da reforma trabalhista nas práticas de admissão, férias e rescisão nas Instituições de Ensino Superior Comunitárias do Rio Grande do Sul, a qual foi desenvolvida principalmente através da interpretação das alteraçôes e inclusôes de novas regras à CLT pela Lei no 13.467 de 2017.

O estudo proporcionou a análise de quais as práticas impactadas pela reforma trabalhista estáo sendo aplicadas nas IES, bem como a identificação de quais foram às medidas necessárias para atendimento às novas demandas.

No intuito de atender as novas demandas, $50 \%$ das IES pesquisadas iniciaram a aplicação das novas regras trabalhistas em algumas práticas, sendo que em algumas necessitam cumprir determinaçóes de convenção coletiva ou até mesmo por questóes estratégicas de gestão da instituição. Entretanto, as demais Instituições estão utilizando pouco às alteraçóes e mantendo algumas regras anteriores, como por exemplo, prazo de pagamento de rescisóes.

Nas práticas de admissão, avaliou-se a aplicação das formas de contratar, sendo o contrato de trabalho intermitente, o teletrabalho e a terceirizaçáo. Para contrato de trabalho intermitente, as IES não estão aplicando está prática, pelo fato de suas atividades não possuírem períodos de inatividade. Igualmente, o contrato de teletrabalho pelo fato de suas atividades serem presenciais. 
No caso da terceirização, na UNISC utiliza-se muito esta forma de contratação para os cursos de especialização ou para os que possuem menor período de duraçáo e menor custo para instituição. Da mesma forma, aplicando a contratação através da terceirizaçáo da atividade fim encontram-se $25 \%$ das demais Instituiçóes da amostra e, as outras $75 \%$ não estão aplicando.

Na prática de férias, a UNISC utiliza-se da flexibilização, pois o fato de poder usufruir do período de férias em até três períodos permite que a instituição consiga organizar a sua estrutura para náo acarretar em acúmulo de atividades nos períodos de férias, assim como para o funcionário torna-se benéfico, pois irá tirar suas férias em momentos distintos durante o ano. Das demais IESs que responderam à pesquisa, $75 \%$ estáo aplicando muito o fracionamento do período de férias, enquanto $25 \%$ destas utiliza está prática razoavelmente.

Na prática de rescisão, a UNISC vem aplicando esta prática assim como $50 \%$ das demais, diferentemente das outras $50 \%$ das Instituiçóes que não estão aplicando esta nova modalidade de rescisão. Para não haver excesso de pedidos de acordo, na UNISC foi criado um regramento interno para que seja aplicada está prática, sendo que o critério é o desligamento para redução de quadro. Sendo assim, quando uma das partes deseja efetivar uma rescisão por acordo e há estratégia definida para reduçáo desta vaga, será aplicada a nova modalidade de rescisão por acordo. Assim como na UNISC, dentre a amostra, 33\% estavam utilizando como critério para estabelecer a rescisão por acordo à redução de quadro, enquanto $67 \%$ possuem critérios estabelecidos e não os informaram.

Para aplicar essas alterações, a UNISC elencou as prioridades a serem aplicadas e esses temas foram verificados pelo setor jurídico. Como medidas de adequação, a UNISC recorreu a treinamentos e cursos para aprimoramento de conhecimentos sobre o assunto, da mesma forma que $43 \%$ das demais Instituiçóes, amostra do estudo. Após, estabeleceu parcerias e troca de informaçóes com outras IES, o mesmo realizado por $29 \%$ das outras Instituiçóes. O mesmo índice de $29 \%$, são as instituiçóes que assim como a UNISC, tiveram que realizar ajustes no seu sistema de TI para atendimento das novas demandas.

Ao final da pesquisa foi possível concluir que as instituiçóes de ensino superior comunitárias do Rio Grande do Sul estão avaliando com cautela a aplicação das mudanças nas práticas de admissão, férias e rescisão, frente à reforma trabalhista, visando manter a boa relação de trabalho com seus funcionários e o atendimento da legislação vigente e as convençóes coletivas de trabalho.

\section{REFERÊNCIAS}

BRASIL. Constituição da República Federativa do Brasil de 1988. Brasília, 5 de outubro de 1988. Disponível em: http://www.planalto.gov.br/ccivil_03/constituicao/ constituicao.htm. Acesso em: 14 abr. 2018.

BRASIL. Lei No 13.467, de 13 de julho de 2017. Altera a Consolidação das Leis do Trabalho (CLT), aprovada pelo Decreto-Lei no 5.452 , de $1^{\circ}$ de maio de 1943 , e as Leis 
$\mathrm{n}^{\mathrm{o}} \mathrm{s}$ 6.019, de 3 de janeiro de 1974, 8.036, de 11 de maio de 1990, e 8.212, de 24 de julho de 1991, a fim de adequar a legislação às novas relações de trabalho. Disponível em: https://legis.senado.leg.br/norma/17728053. Acesso em: 14 abr. 2018.

BRASIL. Decreto-Lei n. 5.452, de $1^{\circ}$ de maio de 1943. Aprova a Consolidação das Leis do Trabalho. Diário Oficial União. Rio de Janeiro, RJ, 1 mai. 1943. Disponível em: http://www.planalto.gov.br/ccivil_03/decreto-lei/Del5452.htm. Acesso em: 14 abr. 2018.

BRASIL. Instrução Normativa RFB n. 936, de 5 maio de 2009. Diário Oficial União. Rio de Janeiro, RJ, 6 mai. 2009. Disponível em: http://normas.receita.fazenda.gov.br/ sijut2consulta/link.action?visao=anotado\&idAto=15897. Acesso em: 14 abr. 2018.

BRASIL. Lei n. 8.036, de 11 de maio de 1990. Dispóe sobre o Fundo de Garantia do Tempo de Serviço, e dá outras providências. Diário Oficial União. Brasília, DF, 11 mai. 1990. Disponível em: http://www.planalto.gov.br/ccivil_03/Leis/L8036consol.htm. Acesso em: 14 abr. 2018.

BRASIL. Lei n. 13.429, de 31 de março de 2017. Altera dispositivos da Lei ${ }^{\circ}$ 6.019, de 3 de janeiro de 1974, que dispóe sobre o trabalho temporário nas empresas urbanas e dá outras providências; e dispóe sobre as relações de trabalho na empresa de prestação de serviços a terceiros. Diário Oficial União. Brasília, DF, 31 mar. 2017. Disponível em: http:/www.planalto.gov.br/ccivil_03/_ato2015-2018/2017/lei/L13429.htm. Acesso em: 28 jun. 2018.

BRASIL. Tribunal Superior do Trabalho. Súmula n. 276, 2003. O direito ao aviso prévio é irrenunciável pelo empregado. O pedido de dispensa de cumprimento não exime o empregador de pagar o respectivo valor, salvo comprovaçáo de haver o prestador dos serviços obtido novo emprego. Disponível em: http://www3.tst.jus.br/jurisprudencia/ Sumulas_com_indice/Sumulas_Ind_251_300.html\#SU\%20M-276. Acesso em: 14 abr. 2018.

CARVAlHO, A. P. N.; CARVALHO NETO, A. C. F.; GIRÃO, H. A. A reforma trabalhista como consequência da necessidade de flexibilização das relaçóes de trabalho diante da evolução da sociedade. Revista de Direito Econômico e Socioambiental, Curitiba, v. 8, n. 3, p. 49-66, set./dez. 2017.

CASSAR, V. B. CLT comparada e atualizada: com a reforma trabalhista. São Paulo: Método, 2017.

HEINEN, A. C. Reforma trabalhista: análise das principais práticas da folha de pagamento. 2017. 64 f. Trabalho de conclusão (Curso de Direito - Especialização) -Universidade de Santa Cruz do Sul, Santa Cruz do Sul, 2017.

MATIAS-PEREIRA, J. Manual de metodologia da pesquisa científica. 3 ed. São Paulo: Atlas, 2012.

OLIVEIRA, A. Manual de prática trabalhista. 39. ed. São Paulo: Atlas, 2006. 
OLIVEIRA, S. E. Reforma trabalhista de 2017: percepçóes dos empregadores e trabalhadores do sul catarinense. 2017. 81 f. Trabalho de Conclusão de Curso Universidade do Extremo Sul Catarinense, Criciúma, 2017.

REIS, A. M. A flexibilização das leis trabalhistas no Brasil como pressuposto para o desenvolvimento econômico do País. 2016. 101 f. Dissertação (Programa de PósGraduação Stricto Sensu em Direito) -Universidade Católica de Brasília, Brasília, 2016.

ROCHA, R. R. Governo Temer: reforma trabalhista, destruição dos direitos dos trabalhadores? 2017. 37 f. Trabalho de Conclusão de Curso - Universidade de Brasília, Brasília, 2017. 